\title{
A formação de professores do ensino liceal. A Escola Normal Superior da Universidade de Coimbra (1911-1930)
}

\author{
António Gomes Ferreirai \\ Universidade de Coimbra, Portugal \\ Luís Motaii \\ Instituto Politécnico de Coimbra, Portugal
}

\begin{abstract}
Resumo
A nossa análise incide sobre o modelo de formação de professores das Escolas Normais Superiores, particularmente sobre a escola anexa à Universidade de Coimbra. Instituições inspiradas na École Normale Supérieur de Paris, marcadas pela pedagogia do movimento da Escola Nova e portadoras de um caráter inovador, peça-chave num projeto educativo mais vasto, encetado pelos republicanos após outubro de 1910, fundado na crença de regenerar a Pátria por via da instrução, fabricando um cidadão novo e construindo a Nação republicana, constituíram a primeira tentativa de formar professores para todos os graus de ensino, com exceção do ensino primário geral. Numa perspetiva teórica e ideal, a legislação traduziu um momento significativo na nossa História da Educação (Gomes, 1990); no entanto, o contexto e as condições - nomeadamente as materiais - impediram-na que se viesse a transformar na escola modelo que se almejava.
\end{abstract}

Palavras-chave

Escola Normal Superior; República; Ensino Normal; Universidade

\section{Introdução}

É possível traçar uma linha da evolução da formação de professores do ensino secundário em Portugal, desde a identificação da necessidade de professores aptos científica e pedagogicamente e da defesa da criação de 
uma escola normal do ensino secundário, primeiro nos atos discursivos dos especialistas (Deusdado, 1973) e depois no dos políticos (Machado, 1888), passando pela criação de um curso livre de Psicologia aplicada à educação (Deusdado, 1892), até à institucionalização do ensino normal secundário, com a criação de dois cursos cuja estrutura de formação articulava os domínios científicos, da especialidade e psicopedagógico, com a componente prática, e que profissionalizavam, um, os futuros professores das disciplinas de Matemática, Ciências Físico-Químicas, Histórico-Naturais e Desenho do plano de estudos dos liceus (Decreto n. ${ }^{\circ} 4,1901$ ), estoutro, o Curso de Habilitação para o Magistério Secundário (CHMS) (Decreto n. ${ }^{\circ} 5,1901$ ), no domínio das ciências do espírito - Geografia, Filosofia, História e Línguas. Este modelo, de reconhecidas limitações, sofreu uma acentuada erosão e não deixou de colher críticas desde muito cedo, nomeadamente por parte de profissionais e especialistas que sustentavam uma outra institucionalização para uma escola de habilitação para o magistério secundário (Nóvoa, 1988) e normal primário (Santos, 1910).

A reivindicação de uma escola normal do magistério liceal não pode deixar de ser perspetivada, numa lógica de atualização de construção da modernidade em Portugal, no campo da Educação. De facto, as propostas educativas, profundamente marcadas pela Educação Nova, conferiam grande relevância a uma pedagogia científica e ao seu conhecimento por parte dos professores. A preocupação com uma educação integral, científica e sistemática fazia com que autores portugueses republicanos, como Aurélio da Costa Ferreira; Alves dos Santos ou Faria de Vasconcelos, pretendessem que a formação de professores devesse dar espaço à pedagogia, à metodologia, à psicologia experimental, de modo que os professores pudessem agir de acordo com as características de cada aluno. A formação de professores era pensada, à imagem da dos médicos, como preparação de profissionais especialmente capacitados para avaliar as condições de aprendizagem dos alunos e para encontrar as soluções mais adequadas para cada caso. Tratase de um discurso portador de marcas de modernidade e, embora isto não constituísse propriamente uma novidade, não há dúvida que o contexto ideológico, especialmente após a instauração da República, propiciava que tais ideias pudessem ser contempladas nas propostas políticas sobre a organização da formação de professores. 
Partindo de um diversificado espólio documental, com destaque para as fontes de arquivo resultantes do exercício da Escola Normal Superior de Coimbra, sem perder de vista os recursos humanos e as vicissitudes do funcionamento e do quotidiano da escola anexa à Universidade de Coimbra, fixamos a nossa atenção em dimensões de um modelo que procurou compaginar a formação de professores do ensino liceal com as leis científicas que deveriam governar a educação, assentes na afirmação da Pedagogia como ciência da educação e no caráter experimental da Psicologia, nomeadamente reconhecendo a importância do conhecimento científico da criança para $\mathrm{o}$ ato educativo. Neste contexto, à Metodologia, componente da Pedagogia e saber-charneira entre o conhecimento científico e a ação de educar, cabia discernir o método, ou os métodos, que permitissem realizar o ideal individual e social da Educação preconizado.

\section{Do plano de estudos ao corpo docente}

Criado pelo Decreto de 21 de maio de 1911, o ensino normal superior constituiu o primeiro momento na história da instrução em Portugal em que a formação de professores, com exceção do ensino primário geral, é atribuída ao ensino universitário acompanhada da criação de instituições para o efeito. As novas Escolas Normais Superiores, funcionando anexas às universidades de Coimbra e Lisboa, tinham como missão "promover a alta cultura pedagógica e habilitar para o magistério dos liceus, das escolas primárias, das escolas primárias superiores, e para admissão ao concurso para os lugares de inspectores" (Decreto de 21 de maio, 1911), contribuindo para a dignificação e valorização da formação de professores e da própria profissão. Um conjunto de razões, com destaque para a condição de admissibilidade, o bacharelato das recém-criadas Faculdades de Letras ou de Ciências, determinou, por um lado, o protelamento do início dos cursos nas escolas normais superiores e, por outro, a necessidade da publicação de um conjunto de normas transitórias que se destinaram a criar as condições para que $04^{\circ}$ ano do Curso de habilitação para o magistério secundário funcionasse, desde logo, no ano letivo de 1911-1912 e até à abertura da Escola Normal Superior, anexa à Universidade de Coimbra. O próprio currículo conheceu diversas alterações legislativas, e quando 'chegou' o 28 de maio de 1926 o plano de estudos em vigor estava datado de 1918 (Decreto n. ${ }^{\circ} 4900$ ), publicado no 
Regulamento das Escolas Normais Superiores das Universidades de Coimbra e Lisboa; contudo, no essencial, manteve o modelo de formação inicial.

$\mathrm{Na}$ verdade, independentemente das vicissitudes da política republicana e dos diferentes projetos sobre a educação, as Escolas Normais Superiores foram vingando, dando sequência à institucionalização de uma formação de profissionais do ensino liceal e do ensino normal primário e primário superior, buscando conferir uma dignidade para estes professores por via da habilitação específica para a docência. $\mathrm{Na}$ medida em que a admissão se realizava com o bacharelato, obtido nas faculdades de Letras ou Ciências, o plano de estudos da Escola Normal Superior cuidava apenas, se nos reportarmos às vertentes enunciadas por Eusébio Tamagnini (1931), da preparação profissional teórica e da prática profissional. Organizada a formação em dois anos, um era dedicado a preparação pedagógica e o segundo à prática pedagógica, a efetuar nos liceus, nas escolas normais primárias ou nas escolas primárias superiores, de acordo com o curso de habilitação frequentado pelos alunos-mestres. $O$ ano de preparação pedagógica possuía um elenco de disciplinas anuais, o que Ihes conferia centralidade no desenho curricular do curso, como a Pedagogia (com exercícios de pedagogia experimental), a História da pedagogia, a Psicologia infantil e a Metodologia geral das ciências do espírito, apenas para os alunosmestres da secção de letras, e a Metodologia geral das ciências matemáticas $e$ a das ciências da natureza, que se destinavam apenas aos da secção de ciências e desenho. As restantes eram cursos semestrais, das quais Organização e legislação comparada do ensino secundário era exclusivamente para o curso de habilitação ao magistério liceal e Organização e legislação comparada do ensino primário, e obras complementares e auxiliares da escola se destinava aos alunos-mestres que frequentavam os cursos de habilitação aos magistérios do ensino normal primário e primário superior.

Neste $1^{\circ}$ ano estavam previstas 3 horas semanais de aulas, sendo uma reservada aos exercícios práticos na forma de conferências (quatro por ano, dois por semestre), exercícios orais sobre a matéria já dada nas lições (doze em cada ano, seis por semestre), exercícios escritos nas aulas sobre a matéria das lições anteriores (três em cada cadeira anual e dois por curso semestral) e um exercício escrito em casa (por cadeira ou curso semestral), 
não perdendo de vista a apreensão dos conteúdos e a capacidade de discorrer sobre os assuntos, mas com a preocupação da preparação profissional, patente na determinação dos professores terem "o máximo cuidado em exigir dos candidatos ao magistério toda a correcção e esmero possíveis na linguagem, tanto falada como escrita" (Decreto . $^{\circ} 4900,1918$ ). Sublinhe-se a preocupação do legislador em definir um quadro legal minucioso e exaustivo, bem patente nesta preocupação normativa, marcadamente racionalizadora e moderna, definindo o tipo e o número de exercícios previstos para cada cadeira e curso semestral, guardando pouco espaço para autonomia das instituições e dos seus profissionais.

Era evidente a aposta numa formação que provocasse adesão ao espírito científico, à observação, à preferência por uma aprendizagem ativa. O legislador preocupado com os conhecimentos concretos e com o seu valor educativo, previa a realização de excursões científicas, nomeadamente "passeios de carácter histórico ou artístico e visitas a escolas, museus, monumentos, estabelecimentos fabris, instalações eléctricas ou hidráulicas" (Decreto $\mathrm{n}^{\circ} 4900,1918$ ).

Os candidatos, aprovados no $1^{\circ}$ ano, realizavam a prática pedagógica relativa à disciplina ou disciplinas do grupo liceal normal primário ou normal superior correspondente à secção a que pertencessem, no $2^{\circ}$ ano, sendo dirigida pelo respetivo professor de metodologia especial Esta opção, não podemos deixar de o salientar, significa um reconhecimento da validade formativa do saber experimental e da experiência profissional, conferindo à articulação entre a teoria e a prática o estatuto de eixo fundamental da formação dos professores.

No ano letivo de 1915-1916, começou a funcionar o $1^{\circ}$ ano na Escola Normal Superior, anexa à Universidade de Coimbra (Gomes,1989). Ao serem anexadas a uma instituição universitária e aí captando o seu corpo docente, as escolas normais superiores tendiam a ser servidas por professores com melhor e mais elevada qualificação. A composição do corpo docente é sempre determinante para a prossecução das políticas educativas, tanto mais quando estas são decididas de forma centralizada e, tantas vezes, sem terem em consideração os recursos disponíveis, muito especialmente os humanos. Mais premente se torna a questão quando se pretendem promover políticas inovadoras, para as quais são necessários recursos devidamente preparados e empenhados, em momentos de transformação social e política mais intensa. 
A fórmula escolhida para a seleção do corpo docente, no âmbito da Universidade, cooptando, em acumulação com outro serviço docente, professores e assistentes, das faculdades de Ciências, Letras e Medicina, traduziu-se, muito provavelmente, numa enriquecedora abordagem com diferentes perspetivas e visões - interdisciplinar, diríamos hoje - da coisa pedagógica e da problemática do magistério, contribuindo, simultaneamente, para o envolvimento, na novel Escola Normal Superior, de diferentes setores da Academia Coimbrã. Contudo, não deixamos de nos interrogar até que ponto essa diversidade e, particularmente, o exercício em acumulação, não terão contribuído para dificultar a emergência de uma cultura de escola e de uma produção científica, no âmbito da educação, mais intensa.

É inegável que a reflexão e a produção científicas, no âmbito da educação, são desiguais entre o corpo docente que abraçou o projeto do ensino normal superior, na Universidade de Coimbra. Mesmo considerando este ponto prévio e posicionando-os num princípio de "agnosticismo pedagógico" (Nóvoa, 2003, p. 7), utilizando como critérios os mobilizados pela atual historiografia da educação para elaborar o dicionário dos educadores portugueses, de que se destaca "a reflexão teórica e a prática educativa" (Nóvoa, 2003, p. 7) dos biografados, parece-nos ser de sublinhar a presença, na referida obra, de $75 \%$ dos professores da Escola Normal Superior de Coimbra, nomeadamente: Augusto Joaquim Alves dos Santos (1866-1924), Eusébio Barbosa Tamagnini de Matos Encarnação (1880-1972), Henrique Teixeira Bastos (1861-1943), João Pereira da Silva Dias (1894-1960), João Serras e Silva (1868-1956), Joaquim de Carvalho (1892-1958), José Joaquim de Oliveira Guimarães (1877-1960), Luciano António Pereira da Silva (18641926) e Maximino José de Morais Correia (1893-1969). Neste corpo docente encontrar-se-ão, de igual modo, diferentes graus de comprometimento e de entendimento do projeto pedagógico e educativo da Primeira República onde, naturalmente, as origens familiares, o percurso individual, a formação académica e científica influenciaram a receção de um património de ideias onde podemos destacar a importância da observação e da experimentação para o conhecimento científico, nomeadamente do conhecimento da criança e da sua importância para o ato educativo, da afirmação da Pedagogia, como ciência da educação, e o seu carácter experimental (e laboratorial), caução 'a pagar' para ser considerada uma ciência, da Psicologia, enfim, também das fórmulas da Escola Nova. 


\section{Formação psicopedagógica e os meios de transmissão da verdade científica}

No ano de preparação pedagógica, as disciplinas de Pedagogia (com exercícios de pedagogia experimental), de História da pedagogia, de Psicologia infantil e as três cadeiras de Metodologia geral possuem uma centralidade que Ihes advém, como já destacámos, desde logo, de constituírem cursos anuais. O curso propunha-se dotar os futuros professores dos ensinos liceal, normal primário e primário superior de um cabedal científico no âmbito das Ciências da Educação e de um "espírito profissional metodizado" (Lima, 1927, p. 21), ou seja, competentes para desempenharem a sua função, realizando as tarefas com ordem, de forma hierarquizada, tendo em vista um fim e adotando um caminho, sem desvios, atingindo os resultados com menor esforço possível. Considerações que colocaram a Metodologia, "a ciência dos métodos pedagógicos" (Nóvoa, 1988, p. 51), no centro do ensino normal, constituindo a Pedagogia e a Psicologia eixos fundamentais de interpretação e de sustentação da dinâmica educativa.

No plano de estudos das escolas normais superiores, as disciplinas de Pedagogia (com exercícios de pedagogia experimental) e de Psicologia infantil constituíram o saber de suporte à ação educativa, num momento em que progressivamente, por ação de uma geração na qual se integra Alves dos Santos, se consolida uma matriz científica no estudo da criança e dos processos educativos (Nóvoa, 2005). Levando em consideração a disciplina de Pedagogia (com exercícios de pedagogia experimental), os sumários correspondentes ao ano letivo de 1929-1930, neste período da responsabilidade de José Joaquim de Oliveira Guimarães, informam que se iniciava com uma noção genérica de Pedagogia, tratando os fins e limites da educação e da ação educativa da hereditariedade, para depois passar às qualidades pessoais e sociais e ao seu aproveitamento na ação educativa. Posteriormente, o tema abordado era a criança, o seu intuito colecionista e a atividade lúdica. $O$ hábito, a atenção e a memória eram os assuntos seguintes. Depois da abordagem da Organização e administração da escola concluía-se com a problemática do método dos testes e a sua apreciação estatística, com estudo da média, mediana e desvio-padrão, a avaliação estatística dos testes e os histogramas e os polígonos de frequência (Arquivo da Universidade de Coimbra). 
A influência da Psicologia parece ter sido bastante forte no contexto das conceções educativas que vingavam na Escola Normal Superior de Coimbra. Eusébio Tamagnini, por exemplo, considerando que o professor, "além de instruir tem de inspirar ideais de harmonia com o espírito do tempo nas múltiplas manifestações do desenvolvimento social" (1927a), discutindo o processo de desenvolvimento de um ideal na fase de crescimento da adolescência, dá a máxima prioridade à vertente emocional. As suas palavras são bem eloquentes:

O desenvolvimento dum ideal comporta um processo intelectual e um processo emocional, mas como o elemento emocional é o mais importante compreendese bem porque o período da adolescência corresponde ao melhor tempo para o seu desenvolvimento. As escolas têm por isso necessidade de organizarem o seu trabalho em referência especial a este facto e à alta influência que no processo adquire a personalidade do professor [...] Mera instrução didáctica não basta visto que o espírito emocional da instrução é o facto de maior importância (Tamagnini, 1927b).

A realização dos exercícios de Pedagogia experimental e Psicologia infantil, no âmbito do Laboratório de Psicologia Experimental da Faculdade de Letras - recorde-se que o seu fundador e principal responsável foi Alves dos Santos (Gomes, 1990) -, constitui uma afirmação da cientificidade das duas disciplinas e como que uma legitimação científica do saber, construído pelos alunos-mestres, através da efetiva experimentação, aproximando-os assim da realidade científica e antecipando, de algum modo, a iniciação à prática pedagógica, componente do $2^{\circ}$ ano. De acordo com a legislação, os exercícios experimentais realizavam-se com as turmas reduzidas a dez alunos e, como o comprovam os trabalhos práticos realizados, a título de exemplo, em 1917, sob a orientação de Augusto Joaquim Alves dos Santos, professor de ambas as disciplinas de 1915 até à data do seu falecimento, em 1924, os alunos levaram a cabo experiências sobre a medida da memória, formas e condições da atenção, o problema da memória, condições psicológicas da atenção, a medida da atenção por meio de tempos de reação (Arquivo da Universidade de Coimbra). O relato de Alves dos Santos dá-nos ainda conta de experiências, nomeadamente, "sobre a capacidade de retenção da memória; sobre a psicometria da atenção; sobre a sugestibilidade das crianças, medida do nível intelectual, pelo método de Binet e Simon (escala métrica da inteligência); e sobre outros problemas das ciências psicológicas e pedológicas" (Gomes, 1990, p. 28). 
Neste mesmo período, e atestando a importância atribuída à observação e ao estudo científico do crescimento da criança, Alves dos Santos realizava, com recurso ao método auxonológico, um estudo sobre o crescimento com os alunos do colégio Moderno, em Coimbra:

As primeiras mensurações foram realizadas, durante os meses de Maio e Junho, do ano de 1918 [...] Em Maio e Junho, deste ano de 1919, ao perfazerem-se doze meses completos, continuou-se este serviço antropométrico, que não pode ser executado em Novembro e Dezembro (fim do $1^{\circ}$ semestre), como convinha, mercê das ocorrências políticas, que perturbaram a vida nacional [...] Foram observados e mensurados (e continuá-lo-ão a ser) 115 alunos, de idades que se acham compreendidas entre os dez e os dezoito anos (Santos, 1919, p. 168).

Alves dos Santos, depois de referir as primeiras medidas e de nos esclarecer qual o grupo de estudo, indica-nos o material pedométrico utilizado, a técnica e as instruções, prosseguindo com a descrição dos resultados, com os quadros e as conclusões a que o estudo permitiu chegar. Estávamos efetivamente, perante um esforço no sentido da cientificação do estudo da criança que servisse de fundamento e orientação da prática de ensino.

Eram os conhecimentos adquiridos no âmbito das disciplinas de Pedagogia Experimental e de Psicologia Infantil, nomeadamente no que consolidavam de conhecimento científico da criança, articulados com os saberes científicos da especialidade, adquiridos previamente no curso de bacharelato das Faculdades de Ciências e de Letras, que habilitavam à compreensão da importância de adotar sempre o caminho mais seguro para a transmissão de conhecimentos, tendo em vista "obter um resultado potencialmente múltiplo com o mínimo de esforço possível" (Lima, 1927, p. 37). Atribuía-se, por isso, capital importância ao facto de os candidatos à docência, nos ensinos liceal, normal primário e primário superior, serem conhecedores da utilização dos mais adequados meios e instrumentos pedagógicos, ou seja, dos "processos e maneiras de ensinar e educar" (Lima, 1927, p.79).

A existência de três cadeiras de Metodologia geral - a das ciências do espírito, a das ciências matemáticas e a das ciências da natureza - no plano de estudos explicitava uma preocupação e implicava uma orientação das disciplinas. Denunciava a ligação entre a componente mais conceptual das 
Ciências da Educação e o saber-ensinar presente na prática pedagógica articulada com a mobilização do saber de ciências como a Pedagogia e a Psicologia, para encontrar os caminhos, as orientações a adotar, para o ensino cumprir os seus objetivos. A adoção de um método era determinada pelo conhecimento das tendências do aluno (Cruz, 1920), os seus interesses e o desenvolvimento da sua inteligência (Barbosa, 1923), daí ser necessário subordinar a escolha do método às necessidades individuais da criança.

A inexistência de uma cadeira de Metodologia, de natureza geral, determinou que as disciplinas de metodologia compaginassem a abordagem duma metodologia geral, científica e pedagógica, e uma outra mais centrada na processologia. A análise da documentação existente, os sumários das disciplinas (Arquivo da Universidade de Coimbra), ainda que de uma fase tardia, e os trabalhos realizados pelos alunos - os relatos das conferências realizadas, os exercícios escritos nas aulas sobre a matéria das lições anteriores (exames de frequência) e o exercício escrito em casa (Decreto n. ${ }^{\circ}$ 4900, 1918) -, entre 1915 e 1930 (Arquivo da Universidade de Coimbra), corroboram a nossa asserção.

O 'apelo', nas disciplinas de Metodologia geral das Ciências, à mobilização do conhecimento da Pedagogia (com exercícios experimentais) e da Psicologia infantil confirma-se na análise aos trabalhos existentes, onde transparece a importância atribuída ao conhecimento da criança, da sua natureza física e psíquica, por parte dos futuros professores dos ensinos liceal, normal primário e primário superior, para que melhor pudessem adequar os processos e os métodos de ensino. O professor devia estar preparado para atender às características dos alunos. Despertar a curiosidade e o interesse da criança tornava imperativa a observação científica da criança e o conhecimento profundo das suas etapas de evolução, e o avanço do conhecimento científico, no âmbito da Pedagogia e da Psicologia infantil, tinha de ter uma tradução na forma de orientar o ensino, pois "sem ensino que interesse, provoca-se a falta de atenção, a fadiga, o desassossego" (Cavacas, 1928), mecanismo de defesa do organismo.

Abordando, no âmbito da cadeira de Metodologia geral das Ciências da Natureza, a experiência como processo de aquisição de conhecimentos, a educação surgia definida como a "aquisição de experiência ou experiências, que possam servir para tornar mais perfeita a adaptação do indivíduo ao 
meio" (Pestana, 1917), enquanto os processos eram caracterizados como "as operações materiais da razão" (Pestana, 1917). Existiam, segundo os trabalhos analisados, três processos de aquisição de conhecimentos: através da autoridade do saber dos outros, da observação direta e, finalmente, da experiência, que consistiria numa observação artificial e condicionada. $\mathrm{Na}$ experiência reconhecia-se a existência de duas categorias de elementos, variáveis e variantes, e para que ela fosse proveitosa tornava-se necessário as variáveis segundo a vontade do ator e que, simultaneamente, as condições permanecessem as mesmas. O recurso à autoridade do saber, reconhecidamente 0 processo mais rápido na transmissão dos conhecimentos, não concedia ao aluno tempo para os perceber, reduzindo a sua capacidade de retenção, e, para além disso, provocava uma atitude mental passiva habitualmente acompanhada da perda de interesse e da capacidade de iniciativa. No que se refere à observação direta, consideravase que se tratava de um processo mais seguro, que permitia uma maior retenção de conhecimentos, pelo que se defendia que o aluno, sempre que possível, devia "adquirir os factos directamente" (Pestana, 1917). O recurso à experiência era tido como o processo adequado e mais eficaz à aprendizagem. Ainda que se reconhecesse $o$ inconveniente de exigir bastante tempo para a sua realização, os resultados justificavam a utilização deste processo pois ele garantia que o fenómeno era melhor apreendido e registado na memória. Segundo Cruz (1920), com este apelo à experiência, a atividade intelectual do aluno elevava-se ao máximo e o seu espírito tornava-se "elástico e original". Como sublinhava na sua conclusão o aluno José Pestana (1917), "a observação e a experiência [constituíam] os melhores processos de aquisição dos factos, habilitando o aluno para a resolução de problemas da vida".

No âmbito da metodologia pedagógica, por distinção da metodologia científica, tratava-se de empregar meios próprios a qualquer ensino. Transparece dos próprios trabalhos dos alunos, em consonância com diferentes manuais de metodologia, que mais do que a preocupação com os conteúdos e a natureza dos fenómenos de cada disciplina, o que estava verdadeiramente em jogo era a natureza da criança. Como eloquentemente expressa Adolfo Lima (1927), em obra publicamente elogiada por Adolphe Ferrière à data da sua publicação, o método ou metodologia pedagógica 
tratava de "ensinar a caminhar, a andar por veredas já conhecidas, já percorridas por tôda ou por muita gente, - pela experiência universal da espécie" (p. 374). Consistia, através da aplicação de um conjunto de processos e de meios, em possibilitar aos alunos uma mais fácil e melhor aprendizagem. Ao método pedagógico atribuía-se-lhe a função de criar, em cada aluno, o método científico, isto é, a observação (Lima, 1927).

A metodologia pedagógica constituía a parte da Pedagogia portadora de um conjunto de meios ativos, que incorporava os métodos que, por sua vez, se subdividiam em processos e formas. É bem verdade que não existia consenso, entre a comunidade científica da época, na utilização destes conceitos, invertendo-se por vezes a sua hierarquização e noutras funcionando como sinónimos. De resto, é algo que transparece nos diferentes trabalhos que consultámos, nomeadamente, variando ao nível das disciplinas de metodologia. Ainda assim, consideramos que os métodos que melhor serviam os fins que vimos identificando, de acordo com os trabalhos compulsados, eram o heurístico e o experimental ou de laboratório.

O método heurístico ou da redescoberta era pouco conhecido em Portugal. Através do método pretendia:-se, de acordo com Carrington da Costa (1930), conduzir a criança a percorrer os mesmos passos dados pela humanidade para fundar a ciência. É a consideração da lei biogenética ou da recapitulação, ainda que aceitando a sua restrição na linha do pensamento de Claparède. A resolução de um problema por si própria traduzia-se, para a criança, num reforço do interesse e, por consequência, num apor de atenção que constituía o ponto de partida de associação de ideias e lembranças, permitindo estabelecer relações entre os novos conhecimentos e os anteriores.

O método era considerado como essencialmente ativo porque, pelo raciocínio e reflexão do aluno, articulados com indicações do professor, colocava o estudante no papel de descobridor dos conhecimentos que se pretendiam ensinar. Tudo o que a criança alcançava resultava do seu trabalho e esforço, com reflexo na formação da própria personalidade, ganhando, para além do gosto pelo trabalho, confiança em si e autoconhecimento. Ao professor competia-lhe esclarecer todos os dados de uma questão, sugerir conhecimentos adquiridos que fossem úteis para a sua resolução, saber esperar pelas conclusões a que o aluno deveria chegar e acompanhar 0 
desenvolvimento do raciocínio do aluno, colocando perguntas ou fazendo sugestões sempre que se justificasse. Um método que, segundo Carrington da Costa (1930), faria com que o ensino deixasse "de ser livresco e verbal, de pura memorização, para procurar desenvolver as faculdades de observação, de raciocínio e juízo" (p. 76).

Considerado especialmente inovador por um conjunto de trabalhos era o método experimental ou de laboratório, que consistia, como definia Quintanilha (1920), "em fornecer as noções matemáticas sob a forma de casos concretos, quer tirados da observação de fenómenos correntes, quer da experimentação no campo das ciências físico-químicas ou histórico naturais".

No seu trabalho, Mercês Monteiro (1917) é de opinião que, ao invés de se apresentar aos alunos mais novos as definições com um aspeto dogmático, deveria respeitar-se a origem experimental da Matemática, recorrendo-se a experiências materiais para que o aluno reconhecesse a necessidade da matemática. O recurso ao jogo e a atividades lúdicas, como o dominó, o loto ou as coleções concretas de objetos, permitiriam ensinar as crianças a contar sem que duvidassem das abstrações naturais indispensáveis. Mercês Monteiro, no seu exercício (1917), sustentava que o aluno, depois de considerar um número suficiente de casos especiais, seria capaz de generalizar e passar ao abstrato.

Socorrendo-se, na sua conferência, dos conhecimentos da Pedagogia e da Psicologia, Maria Helena Ferreira de Castro considerava que a condição primeira para que os alunos aproveitassem o ensino era que tivessem interesse pelo que se lhes ensinava. No caso particular da Matemática, sublinhava a necessidade de atender a este fator psicológico, mesmo com sacrifício da exatidão das proposições. O professor deveria empenhar-se em despertar o interesse dos seus alunos, embora tivesse de sacrificar, por vezes, a ordem e o rigor que caracterizavam a Matemática, bastando que aproveitasse a curiosidade natural da criança, uma vez que, como afirmava o aluno relator, qualquer criança questiona os factos que observa. Considerava que para a criança só poderia despertar interesse o que estivesse em relação direta com a sua observação e a sua atividade. Os problemas que o professor de Matemática deveria passar aos seus alunos nunca deveriam ser alheios à sua experiência e observação, única maneira de obter a sua curiosidade pela solução de problemas (Alcântara, 1930). 
Na medida em que a ciência, fundada na experiência e na observação, tinha demonstrado que era mais difícil adquirir uma noção nova do que aqueloutra ligada com outras já apreendidas, os modernos pedagogos aconselhavam, ainda de acordo com a conferencista, que se realizasse o estudo da Matemática de modo a relacionar os diferentes capítulos da Matemática entre si e com outras disciplinas, especialmente com a Física e a Geografia. Acreditava Maria Helena Castro que ao colocar em evidência estas relações, sempre que surgisse a oportunidade, o aluno mais facilmente lixaria as novas noções (Alcântara, 1930).

A preocupação em captar a atenção e o interesse da criança partindo da sua observação e da sua atividade, a consideração de as noções a adquirir serem a partir de e interligadas com outras já adquiridas, a condução da aprendizagem do concreto para o abstrato, o recurso ao jogo e às atividades lúdicas constituem um conjunto de ideias que sublinha a mediação, no âmbito das disciplinas de Metodologia geral, entre o conhecimento teórico e aquele mais prático e, paralelamente, coloca-nos no centro do discurso de afirmação da Pedagogia enquanto ciência da educação, aglutinador de saberes e fortemente marcado pelas ideias da Escola Nova.

\section{Vicissitudes de um projeto}

As condições de existência da Escola Normal Superior de Coimbra evidenciam bem - o que em grande medida é válido para as instituições de ensino normal criadas durante a Primeira República, em particular, e a Educação, em geral - o grande desejo de mudança que animava muitos dos intelectuais republicanos e a dificuldade que os sucessivos governos experimentaram em concretizar um ideário educativo não só enunciado em muitas ocasiões, e em imensas publicações, como também em vários diplomas legais, seja por questões de ordem material ou orçamental, ou em razão da divergência de ideias em função da sua concretização.

Logo em 1914, ainda não existiam bacharéis para frequentarem as escolas normais superiores, já uma Representação do Senado universitário, dirigida ao Ministro da Instrução Pública, apelava à não execução da lei orçamental (Lei n. $\left.{ }^{\circ} 226,1914\right)$ que facultava a abertura de vagas do quadro aos professores provisórios dos liceus, prejudicando "nos seus mais legítimos 
interesses" (Representação de 9 de Julho, 1914) os alunos das Faculdades de Ciências e de Letras, ameaçando a sua saída profissional. $O$ documento, assinado pelo Reitor da Universidade e pelos diretores das duas faculdades, consubstancia uma crítica mais profunda ao funcionamento das instituições e ao comportamento da classe política, acusada de tomar decisões precipitadas e sem discutir devidamente assuntos da maior relevância como explicitamente se diz na Representação:

Tratou-se de um assunto tão importante, como é a selecção do professorado, numa lei orçamental votada precipitadamente, sendo as suas disposições causa de verdadeira surpresa. Não houve sobre tal assunto o mínimo debate parlamentar, em que se ponderassem os efeitos que, da medida proposta e aprovada, resultariam. Os interessados não puderam formular as suas pretensões, que deveriam ser tomadas na devida consideração [...] Protestam agora contra a lei (...)

A medida, que servia interesses de "professores sem curso, nem concurso" (Gomes, 1989, pp. 31-36), traduz o atraso e o desfasamento entre o ensino normal secundário e as necessidades colocadas pelo crescimento do ensino liceal que, na falta de professores habilitados, socorreu-se dos recursos humanos disponíveis. Situação semelhante, de resto, se viverá no ensino normal primário por força do ritmo de desenvolvimento das Escolas Normais Superiores. A crueza da realidade entrava em contradição com os ideais e os anseios dos atores, políticos e sociais.

Em 1916 a escola esteve encerrada desde fevereiro, tendo todos os professores pedido a sua exoneração sem que a Academia coimbrã conseguisse encontrar, entre os docentes das faculdades, quem estivesse disponível para os substituir.

As limitações orçamentais que, em muitos casos, se revelaram determinantes na ação, ou na ausência dela, do Estado e dos sucessivos governos da Primeira República, afetaram decisivamente o funcionamento e o quotidiano da Escola Normal Superior de Coimbra. O facto de nunca se terem iniciado as aulas aquando da abertura regular do ano letivo, uma vez que o Estado não nomeava júris de admissão por falta de verba para pagar aos professores ou por a ter desviado para outros fins (Tamagnini, 1931), confirma, em nosso entender, isso mesmo. Eusébio Tamagnini, diretor da Escola, não se cansará de denunciar até que ponto as dificuldades de funcionamento da instituição que dirigia eram devidas a fatores externos à 
própria instituição e ao seu corpo docente. No primeiro número do Arquivo Pedagógico, já em plena ditadura nacional, escreverá, a abrir a publicação:

No presente ano lectivo as aulas ainda não abriram, nem se faz ideia de quando isso será! De quem é a culpa? Desanexaram-se as Escolas Normais Superiores das respectivas Universidades. Foram ouvidos os professores de Coimbra sobre as vantagens ou desvantagens dessa desanexação? Não foram! Consumado o facto, discutido o assunto, como é que pretendeu corresponder ao desinteresse pessoal e ao ardor profissional com que os professores de Coimbra defenderam os seus pontos de vista? Tentando suprimir a sua Escola!! [...] O público precisa conhecer este e outros factos para apreciar a situação e julgar as nossas acções (Tamagnini, 1927a).

A presença de diferentes respostas para os constrangimentos orçamentais e a falta de consenso na sociedade portuguesa para os caminhos a trilhar na edificação e consolidação de um ensino normal secundário adquiriu alguma visibilidade a partir do segundo lustro da década de 20 do século passado e contribuiu para um significativo consumo de energias por parte do corpo docente da Escola Normal Superior, da Universidade de Coimbra, o que não pode ter deixado de afetar o seu funcionamento. De 1924 a 1930 a instituição foi sujeita a um processo de extinção (e renascimento) necessariamente desgastante. Afetou, nomeadamente, todos aqueles que contribuíam para o seu funcionamento e, quiçá, com consequências no 'serviço' prestado, para utilizar uma expressão atual. Vejamos.

Em outubro de 1924, o Ministro da Instrução Pública, António Abranches Ferrão, remodelava o ensino normal superior em nome da "situação do Tesouro Público" (Decreto n. $\left.{ }^{\circ} 10.205,1924\right)$. Extinguia a Escola Normal Superior de Coimbra e reduzia a metade a duração da maior parte das cadeiras e cursos. No preâmbulo afirmava-se que tais medidas não tinham "o menor inconveniente pedagógico [e possuíam] toda a vantagem económica" (Decreto n. ${ }^{\circ}$ 10.205, 1924). Três meses e meio depois, em face das representações do Senado e da Associação Académica, o ministro António Joaquim Sousa Júnior restabelece a Escola Normal Superior, da Universidade de Coimbra.

Dois anos mais tarde, em 1926 (Decreto n. ${ }^{\circ} 12.426,1926$ ), as escolas normais superiores foram desanexadas das respetivas universidades. $\mathrm{Na}$ Universidade de Coimbra iniciava-se, aqui, uma intensa semana de reuniões, 
entre quarta-feira, dia 8, e terça-feira, dia 14 de dezembro de 1926. A 8, o conselho da Escola Normal Superior reuniu e denunciou a política do facto consumado, considerando que a tomada de decisão ocorreu sem consulta da Escola e apresentava o que considerava serem as desvantagens pedagógicas e financeiras da desanexação, para além de a considerar uma medida contra os interesses universitários (Gomes, 1989, pp. 277-280). A 12 do mesmo mês, por correrem rumores merecedores de preocupação, indiciando a vontade de extinção da Escola Normal Superior, na ausência do seu diretor, que se encontrava a diligências em Lisboa, o professor mais antigo, José Joaquim de Oliveira Guimarães, convocou reunião do Conselho, onde se aprovou que o Presidente deveria dirigir um ofício ao Senado universitário onde justificaria a conservação da Escola Normal Superior. Assim fez, apresentando razões de ordem doutrinal e de ordem económica. No dia seguinte, o Conselho reuniu novamente tendo o diretor dado conta da reunião com o ministro e as garantias dadas pelo responsável político em como o diretor seria sempre ouvido antes de qualquer decisão ser tomada. A 14, o Senado universitário, em resposta ao ofício da Escola, aprova uma moção solicitando do ministério a "rápida regulamentação das Escolas Normais Superiores" (Gomes, 1989, pp. 287291). Por causa da tomada de posição da escola e do seu corpo docente e da Universidade, ou não, o governo acabou por revogar a desanexação no primeiro trimestre de 1927 (Decreto $\mathrm{n}^{\circ}{ }^{0}$ 13.296, 1927).

Um ano após a reanexação, precisamente em março de 1927, em "virtude dos boatos de extinção da Escola Normal Superior", o Conselho aprovou uma moção em que, para "a salvação da sua Escola", os professores dispunham-se a "fazer gratuitamente o serviço". No mês seguinte a escola seria extinta (Decreto . $^{\circ} 15.365,1927$ ). Seguiu-se uma carta dos professores da Escola Normal Superior de Coimbra ao Ministro da Instrução Pública (Carta dos Professores, 1928, pp. 248-253) que, conjuntamente com outras reações, os interesses dos alunos, as necessidades do sistema educativo e a insuficiência de uma só escola normal superior (Decreto n. ${ }^{\circ} 16.078,1928$ ), provocou o recuo do governo (Gomes, 1989, pp. 308-311). Ganhou mais um fôlego, mas foi apenas isso. Encerrando um processo que se arrastou seis anos, com início ainda na Primeira República e que atravessou quase todo o período da Ditadura Nacional, as escolas normais superiores foram extintas em outubro de 1930 (Decreto n. ${ }^{\circ 1} 18.973,1930$ ). 
As críticas insertas no preâmbulo do decreto que extinguiu as escolas, bem como as difundidas na imprensa, foram merecedoras de uma resposta do último diretor da Escola Normal Superior, anexa à Universidade de Coimbra. Criticando a extinção das escolas normais superiores e a alternativa adotada para a formação de professores para o magistério secundário, dava conta da importância da existência das referidas escolas e do seu significado para a qualidade da formação dos professores do ensino liceal. No combate às ideias constantes do decreto de extinção contrapôs as responsabilidades do Estado, nomeadamente do ministério da tutela, nas dificuldades do funcionamento das referidas escolas e apresentou alternativas, há muito reclamadas pelo corpo docente da escola que dirigira.

Quanto às críticas e ataques ao profissionalismo e competência dos professores, manifestou estranheza face à gravidade das acusações e não compreender que não dessem lugar a qualquer inquérito ou sindicância (Tamagnini, 1931). Na verdade, quando seis anos mais tarde são suspensas as matrículas nas escolas do magistério primário, o governo acautelará a situação, determinando a abertura de um inquérito à Escola do Magistério Primário de Coimbra, em resultado de uma campanha previamente construída na imprensa regional (Mota, 2007).

$\mathrm{Na}$ tentativa de lançar alguma luz sobre o impacto real da formação na Escola Normal Superior da Universidade de Coimbra podemos coligir e corrugar elementos dos anuários estatísticos, de Portugal e da Universidade de Coimbra. Consideremos aqui apenas os anos letivos de 1917-1918 a 1920-1921 numa tentativa de elucidar a escala da instituição e da sua oferta educativa.

No ano letivo de 1917-1918 frequentavam o $1^{\circ}$ ano 18 alunos e 17 o $2^{\circ}$, num total de 35 . Um aluno frequentava o curso do magistério normal primário, os restantes estavam matriculados no magistério liceal. Nesse ano letivo, 5 alunos ficaram aprovados no Exame de Estado, 4 para o magistério liceal e 1 para o ensino normal primário. No ano letivo de 1918-1919, dos 36 alunos, 2 frequentavam o curso do magistério primário e os restantes o curso do magistério liceal. Dezanove alunos, do curso do magistério liceal, foram aprovados no Exame de Estado. Nos anos lectivos de 1919-1920 e 19201921, a escola teve, em cada um desses anos letivos, 46, distribuídos do seguinte modo: 40 no curso do magistério liceal, 4 no magistério normal 
primário e 2 no curso do magistério primário superior. Em 1919-1920, 12 alunos, 10 do curso do magistério liceal e 2 do primário superior, ficaram aprovados no Exame de Estado. Já no ano letivo seguinte, também 12 alunos ficaram aprovados; contudo, todos pertenciam ao curso do magistério secundário. Neste período frequentaram a Escola cerca de 161 alunos, 91 no $1^{\circ}$ ano e 70 a realizar a prática pedagógica, embora apenas 48 ficassem aprovados no exame de Estado. Da análise a este quadriénio resulta uma média de 12 alunos profissionalizados em cada ano e, se definíssemos um ratio entre alunos aprovados no Exame de Estado e os professores do ano de preparação pedagógica e os das metodologias especiais, o cálculo daria cerca de 2,5 alunos profissionalizados, por professor, em cada um destes anos letivos. Resultados que, mesmo atendendo às taxas de escolarização do país e de frequência do ensino liceal, bem como à densidade da rede escolar do ensino liceal do primeiro quartel do século $X X$ e ao período de tempo analisado, ilustram bem as dificuldades e as limitações que o projeto de ensino normal superior experimentou.

\section{Conclusão}

A Escola Normal Superior de Coimbra viveu, ao longo de toda a sua existência, diversas vicissitudes e, se ao nível retórico constituiu um momento significativo na nossa História da Educação, o mesmo já não se pode afirmar quanto ao seu funcionamento, ficando muito aquém do que seria desejável, como de resto deixam transparecer relatos da época, seja na imprensa ou nos relatórios do seu diretor.

Não há dúvida que as ideias pedagógicas que marcavam o discurso republicano eram generosas e adequadas a uma visão de mundo progressista que acreditava muito na capacidade de regeneração das pessoas, quando educadas com base no primado da ciência e numa pedagogia moderna, mas também parece evidente ter existido uma enorme capacidade de colocar em ação essas ideias.

Para além das alterações frequentes do dispositivo legislativo, de diversa ordem e razões de diferente natureza - cujo impacto no funcionamento e no quotidiano da Escola Normal Superior de Coimbra não é demais sublinhar -, o próprio modelo obriga-nos a questionar a sua eficácia 
na formação de professores dos ensinos liceal, normal primário e primário superior e qual o seu impacto na transformação das práticas tradicionais, quando, apesar do investimento na pedagogia experimental por nós assinalado, tudo se parece conjugar para a manutenção duma didática clássica, assente no método expositivo, tanto mais que as três horas por semana de aula apontavam mais para a tendência de se centrar na transmissão de um conjunto de conteúdos pedagógicos em voga desde o início do século $X X$ do que no seu exercício. Este modelo de formação apresenta, em nosso entender, dois aspetos nevrálgicos que interessa ter em atenção: por um lado, a sua natureza sequencial leva-nos a questionar a articulação entre as dimensões científicas, ou seja, entre os saberes da especialidade e os do domínio psicopedagógico, e, por outro, a articulação destes com a prática pedagógica, realizada nos liceus, escolas normais primárias ou escolas primárias superiores e onde, aparentemente, o único contacto ocorria com a visita mensal do professor de Pedagogia ou de História da Pedagogia. Preocupações, de resto, que encontraram um certo eco no relatório que antecedia o decreto da extinção das escolas normais superiores (Tamagnini, 1931).

Independentemente do conhecimento que possamos vir a ter com estudos mais aprofundados sobre o funcionamento dos diferentes estabelecimentos de formação de professores no período em causa, a efémera existência da Escola Normal Superior da Universidade de Coimbra, durante a Primeira República e a Ditadura Nacional, mostra que não só não estava verdadeiramente consolidada uma formação de professores do ensino secundário de acordo com a modernidade cientificista cara aos pedagogos republicanos, como não se tinha conseguido difundir um pensamento pedagógico e generalizar uma prática educativa que obstasse a que fosse perdendo terreno o entusiasmo por políticas educativas mais desenvolvimentistas e mais próximas de modelos pedagógicos que se inseriam no movimento da Escola Nova. Com o esgotar da Primeira República abriam-se outras possibilidades de entendimento da educação que, refutando alguns dos principais pressupostos do ideário republicano, estiveram na base das alterações sobre a formação de professores que surgiram na década de trinta do século $\mathrm{XX}$. 


\section{Referências}

Alcântara, M. C. (1930). Relatório de conferência na cadeira de Metodologia das Ciências Matemáticas "Método Experimental (ou de Laboratório) nas Matemáticas Elementares". Por Maria Helena Guimarães Ferreira de Castro, 28 de fevereiro de 1930. Arquivo da Universidade de Coimbra. Escola Normal Superior de Coimbra - Alunos - Conferências. Dissertações. Exercícios Escritos II. Caixa IV 2a E 9-5-20.

Barbosa, A. (1923). Os métodos das ciências matemáticas. Métodos de indução e dedução. Depósito da Faculdade de Letras da Universidade de Coimbra.

Cavacas, A. A. (1928). Considerações psicopedagógicas para a orientação da didáctica geral. Arquivo Pedagógico. Boletim da Escola Normal Superior de Coimbra, vol. II, $n^{\circ} 1,21-28$.

Costa, R. C. (1930). Método heurístico. Arquivo Pedagógico. Boletim da Escola Normal Superior de Coimbra, vol. IV, 69-86.

Cruz, M. A. B. (1920). Relatório da Conferência realizada em 12 de Junho de 1920 pelo aluno Manuel Dias Fernandes subordinada ao título "Método indutivo e dedutivo". Depósito da Faculdade de Letras da Universidade de Coimbra.

Deusdado, M. F. (1892). Psicologia aplicada à educação. Lição de abertura exposta no Curso Superior de Letras de Lisboa no ano de 1891-1892. Revista de Educação e Ensino, Ano VII, 49-70.

Deusdado, M. F. (1973). A necessidade da preparação pedagógica no professorado português. In A. Ferreira (Org.), Antologia de textos pedagógicos do século XIX português - vol. II (pp. 331-346). Lisboa: Instituto Gulbenkian de Ciência/Centro de Investigação Pedagógica.

Gomes, J. F. (1989). A Escola Normal Superior da Universidade de Coimbra (19111930). Lisboa: Instituto de Inovação Educacional.

Gomes, J. F. (1990). As origens do Laboratório de Psicologia Experimental da Universidade de Coimbra. Revista Portuguesa de Pedagogia, Ano XXIV, 3-38.

Lima, A. (1927). Metodologia. Lições de metodologia professadas na Escola Normal Primária de Lisboa - vol. I. Lisboa: Livraria Ferin.

Machado, B. (1888). Affìrmacões públicas 1882-1886. Coimbra: Imprensa da Universidade.

Monteiro, M. J. L. (1917). Exercício de metodologia de Ciências Matemáticas. Método de Laboratório. Arquivo da Universidade de Coimbra. Escola Normal Superior de Coimbra - Alunos - Conferências. Dissertações. Exercícios Escritos II. Caixa IV $2^{\mathrm{a}}$ E 9-5-20.

Mota, L. (2007). Confronto ideológico nos primórdios do Salazarismo: Uma campanha contra a Escola do Magistério Primário de Coimbra. Estudos do Século XX, 7, 207-227.

Nóvoa, A. (1988). A república e a escola. Das intenções generosas ao desengano das realidades. Revista Portuguesa de Educação, 1(3), 29-60.

Nóvoa, A. (2005). Evidentemente. Histórias da Educação. Porto: Edições ASA.

Nóvoa. A. (Dir.). (2003). Dicionário de educadores portugueses. Porto: Edições ASA. 
Pestana, J. V. G. (1917). Processo de instrução na Escola Secundária. A experiência como processo de aquisição de conhecimentos, suas características e valor pedagógico. Arquivo da Universidade de Coimbra. Escola Normal Superior de Coimbra - Alunos - Conferências. Dissertações. Exercícios Escritos I Caixa IV $2^{\mathrm{a}} \mathrm{E}$ 9-5-19.

Quintanilha, A. P. S. (1920). Metodologia das Ciências Matemáticas. O método de Laboratório no Ensino Secundário. Depósito da Faculdade de Letras da Universidade de Coimbra.

Santos, A. (1910). A nossa escola primária (o que tem sido, o que deve ser). Porto: Casa Editora de A. Figueirinhas.

Santos, A. (1919). Educação Nova. As bases. I - O corpo da criança. Porto/Rio de Janeiro: Livraria Chardron/Livraria Francisco Alves.

Tamagnini, E. (1927a). Duas palavras. Arquivo Pedagógico. Boletim da Escola Normal Superior de Coimbra, vol.1, $\mathrm{n}^{\circ} 1,1-4$.

Tamagnini, E. (1927b). Questões de educação secundária. Arquivo Pedagógico. Boletim da Escola Normal Superior de Coimbra, vol. 1, n 1, 27-28.

Tamagnini, E. (1931). A extinção das Escolas Normais Superiores. Arquivo Pedagógico. Boletim da Escola Normal Superior de Coimbra, vol. IV, nºs 1 a 4, 101-204.

\section{Legislação}

Decreto de 21 de maio (24 de maio de 1911). Diário de Governo, n. ${ }^{\circ} 120$.

Decreto n. ${ }^{\circ} 4$, de 24 de dezembro (28 de dezembro de 1901). Diário do Governo, $n .^{\circ}$ 294.

Decreto n. ${ }^{\circ} 4900$, de 5 de outubro (18 de outubro de 1918). Diário do Governo, la Série, n. ${ }^{\circ} 229$.

Decreto n. ${ }^{\circ}$, de 24 de dezembro (28 de dezembro de 1901). Diário do Governo, n. ${ }^{\circ}$ 294.

Decreto n. ${ }^{\circ} 10.205$, de 22 de outubro (22 de outubro de 1924). Diário de Governo, $I^{a}$ Série, $n .^{\circ} 237$.

Decreto n. ${ }^{\circ}$ 12.426, de 2 de outubro (2 de outubro de 1926). Diário de Governo, I ${ }^{a}$ Série, n. ${ }^{\circ} 243$.

Decreto n. ${ }^{\circ} 13.296$, de 11 de março (I7 de março de 1927). Diário de Governo, la Série, $n .^{\circ} 55$.

Decreto n. ${ }^{\circ} 15.365$, de 12 de abril (14 de abril de 1927). Diário de Governo, ${ }^{a}$ Série, $n .{ }^{\circ}$ 85.

Decreto n. ${ }^{\circ} 16.078$, de 19 de outubro (26 de outubro de 1928). Diário de Governo, ${ }^{a}$ Série, $n .^{\circ} 247$.

Decreto n. ${ }^{\circ} 18.973$, de 16 de outubro (28 de outubro de 1930). Diário de Governo, $I^{a}$ Série, $n .^{\circ} 251$.

Lei n. ${ }^{\circ} 226$, de 30 de junho (28 de julho de 1914). Diário de Governo, I Série, $n .^{\circ} 127$.

Representação de 9 de julho (23 de julho de 1914). Diário de Governo, II. ${ }^{a}$ Série, $n .^{\circ}$ 170. 


\section{Outros documentos}

Anuário da Universidade de Coimbra. Ano letivo de... Coimbra: Imprensa da Universidade, 1918.

Anuário Estatístico de Portugal. Lisboa: Ministério das Finanças. Direção Geral da Estatística Repartição Central. [Consultámos os anos de 1917, 1919. 1921, 1923, 1924, 1925, 1926, 1927, 1928, 1929 e 1930].

Arquivo da Universidade de Coimbra. Escola Normal Superior de Coimbra - Alunos Conferências. Dissertações. Exercícios Escritos I. Caixa IV 2a E 9-5-19.

Arquivo da Universidade de Coimbra. Escola Normal Superior de Coimbra - Alunos Conferências. Dissertações. Exercícios Escritos II. Caixa IV 2 ${ }^{\mathrm{a}}$ E 9-5-20.

Arquivo da Universidade de Coimbra. Escola Normal Superior de Coimbra Documentos diversos. Caixa IV $2^{\mathrm{a}}$ E 9-5-17.

Carta dos Professores da Escola Normal Superior da Universidade de Coimbra ao Ministro da Instrução Pública (1928). Arquivo Pedagógico. Boletim da Escola Normal Superior de Coimbra, vol. II, 248-253.

Moção (1928). Arquivo Pedagógico. Boletim da Escola Normal Superior de Coimbra Vol. II, 246-248. 
TEACHER TRAINING FOR SECONDARY SCHOOL. THE ESCOLA NORMAL SUPERIOR DA UNIVERSIDADE DE COIMBRA (1911-1930)

Abstract

Our analysis focuses on the model of teacher training from Escolas Normais Superiores, particularly concerning the school belonging to the University of Coimbra. Inspired by the École Normale Supérieure in Paris, those institutions were marked by the pedagogy of the New School Movement, carrying innovative proposals. A key part of a wider educational project initiated by Republicans after October 1910, founded on the belief of regenerating homeland by education, the creation of a new citizen and the building of the Republican nation, these institutions constituted the first attempt to train teachers on all levels of education, except the general primary education. On an ideal and theoretical perspective, the legislation meant a significant milestone in our history of education (Gomes, 1990). However, the context and conditions, including materials, prevented the school from becoming the desired model.

Keywords

Escola Normal Superior; Republic; Teacher training; University

LA FORMATION DES ENSEIGNANTS DU SECONDAIRE. L'ÉCOLE NORMALE SUPÉRIEURE DE L'UNIVERSITÉ DE COIMBRA (1911-1930)

\section{Résumé}

Notre analyse met l'accent sur le modèle de formation des Écoles Normales Supérieures de formation des enseignants, particulièrement sur l'école rattaché à l'Université de Coimbra. Institutions inspirées par l'Ecole Normale Supérieure de Paris, marquées par la pédagogie du mouvement d'École Nouvelle et avec un caractère novateur, un élément-clé dans un grand projet 
éducatif, commencé par les républicains après Octobre 1910, fondé sur la croyance de la régénération de la patrie au moyen de l'instruction, fabrication d'un nouveau citoyen et l'édification de la nation républicaine, a constitué la première tentative pour former les enseignants pour tous les niveaux de l'éducation, à l'exception de l'enseignement primaire général. Dans une perspective théorique et idéale, la Loi traduit un moment important de notre histoire de l'éducation (Gomes, 1990); malgré tout, le contexte et les conditions notamment matérielles l'empêchait de devenir l'école modèle désiré.

Mots-clé

École Normale Supérieure; République; Éducation Normale; Université

Recebido em março, 2012 Aceite para publicação em agosto, 2013

i Faculdade de Psicologia e de Ciências da Educação, Centro de Estudos Interdisciplinares do Século XX, (CEIS20), Universidade de Coimbra, Portugal.

ii Escola Superior de Educação, Instituto Politécnico de Coimbra, Centro de Estudos Interdisciplinares do Século XX (CEIS20), Portugal

Toda a correspondência relativa a este artigo deve ser enviada para: Luís Mota, Rua Dom João III

- Solum, 3030-329 Coimbra. E-mail: mudamseostempos@gmail.com 